\title{
Flow Cytometric Diagnosis of Acute Leukemia and Aberrant Antigen: Sohag University Experience
}

\author{
Elham 0. Hamed*, Abeer Fakher El-Deen \\ Departments of Clinical Pathology, Faculty of Medicine, Sohag University, Sohag, Egypt \\ Email: *elhamomar@yahoo.com
}

How to cite this paper: Hamed, E.O. and El-Deen, A.F. (2018) Flow Cytometric Diagnosis of Acute Leukemia and Aberrant Antigen: Sohag University Experience. Open Journal of Blood Diseases, 8, 37-48. https://doi.org/10.4236/ojbd.2018.82005

Received: March 31, 2018

Accepted: June 23, 2018

Published: June 26, 2018

Copyright ( 2018 by authors and Scientific Research Publishing Inc. This work is licensed under the Creative Commons Attribution International License (CC BY 4.0).

http://creativecommons.org/licenses/by/4.0/

\section{c) (i) Open Access}

\begin{abstract}
Background: Multiparameter flow cytometry is the most important method for the lineage assignment and maturational analysis of acute leukemias (AL) cells. The multi parametric immunophenotyping analysis allows the detection of aberrant antigen expression and the analysis of heterogeneity and clonality of malignant cells in AL. The aim of the work is to study the immunophenotypes of blasts from patients with AL and determine the frequency of aberrant markers. Subjects and Methods: Retrospective study to analyze immunophenotypic data of de novo $144 \mathrm{AL}$ patients who were diagnosed in Clinical Pathology Department, Sohag University. Results: We found that $61.8 \%$ of AL patients were classified as acute myeloblastic leukemia (AML) while 38.9\% classified as acute lymphoblastic leukemia (ALL). The commonest FAB subtype in AML group was AML-M2 (31.8\%) followed by M4-M5 27.3\%. As regard ALL, there were $85.7 \%$ with B-ALL and $14.3 \%$ with T-ALL. The aberrancy expressions were found in 66 of AL cases (45.8\%), CD7 was the most commonly expressed lymphoid antigen in AML (25\%), CD13 was the most commonly expressed myeloid antigen in ALL (39.3\%). Conclusion: The multi parametric immunophenotyping analysis of $\mathrm{AL}$ is sufficient for diagnosis and classification of leukemia. The frequencies of aberrant markers in AL were matched with many published data.
\end{abstract}

\section{Keywords}

Acute Leukemia, ALL, AML, Immunophenotyping, Aberrant Markers

\section{Introduction}

Acute leukemias are a heterogeneous group of malignancies with varying clinical, morphologic, immunologic, and molecular features and display characteris- 
tic patterns of surface antigen expression known as cluster of differentiation antigens (CD), which can be detected by flow cytometry method. Immunophenotyping improves both accuracy and reproducibility of acute leukemia classification [1].

The majority of acute leukemia cases expresses specific lineage markers; however, aberrant immunophenotypes can be detected in a variable number of cases, and it is of clinical importance not only for the accurate diagnosis, but also it has been shown to be useful for providing prognostic information and in detection of minimal residual disease [2] [3]. Its ability to measure multiple parameters on individual cells in a suspension at high speed is ideal for the study of leukemic cells [4].

Aberrant phenotypes in acute leukemia are defined as patterns of antigen expression on neoplastic cells different from the process of normal hematopoietic maturation due to their abnormal genetic program [5]. Many studies consider that the aberrant antigen expression is of a prognostic value and has an adverse effect on clinical response, remission rate and overall survival in patients with acute leukemia [6] [7].

We aimed to study the immunophenotypes of blasts from patients with $\mathrm{AL}$ and determine the frequency of aberrant markers.

\section{Subjects and Methods}

\subsection{Subjects and Study Design}

A retrospective study, we evaluated de novo 144 acute leukemia patients at Sohag university hospital from June 2015 to June 2017. Their age ranged from 2 90 years (median 40 years). There were 108 males (75\%) and 36 females (25\%). All participants were subjected to full history and clinical examination. The analyzed samples were peripheral blood (PB) and bone marrow aspirate (BM). Acute myeloid leukemia cases included in this study were classified according to French-American-British Cooperative Group (FAB) criteria while ALL cases were classified immunologically according to the available immune markers. Exclusion criteria: relapsed, recurrent cases or patients under treatments. It was approved by the faculty committee for research ethics. Informed consent was obtained from the patients or subjects' parents.

\subsection{Methods}

A total of $5 \mathrm{~mL}$ of venous blood sample was collected from each patient and dispensed into a K2-EDTA tube for CBC on cell Dyne-2700 fully automated cell counter. Bone marrow aspirations were also performed for all patients. For morphologic examination, all $\mathrm{BM} / \mathrm{PB}$ smears were air dried and subsequently stained with Leishman's stain to be examined microscopically.

\subsection{Flow Cytometric Analysis}

The analyzed samples were either of $\mathrm{PB}$ or $\mathrm{BM}$ according to availability and 
presence of blast cells in considerable percentage. Fresh PB or BM samples were kept at ambient temperature and processed for immunophenotyping within 6 hours of collection using EPICSXL Coulter Flow Cytometer (Coulter Corporation-USA). The EDTA anticoagulated BM sample was diluted 1:3 with phosphate buffered saline (PBS), pH7.4 (Sigma Chemicals, St Louis). Peripheral blood samples were diluted 1:1. The final cell count suspension was adjusted between 5 and $10 \times 10^{3} / \mathrm{ml}$. For each sample, a set of tubes was prepared for a panel of fluorescein isothiocyanate (FITC)/phycoerythrin (PE) conjugated MoAbs used for diagnosis of acute leukemia including one for the isotypic matched negative control (supplied by Beckman Coulter, France), B-lineage markers (CD19, CD22, CD10, cCD79a), T cell markers: (CD2, CD3, cCD3, CD5, CD4, CD8, CD7). Myeloid markers: (CD13, CD33, intracellular MPO, CD117, CD61, CD41, CD42, CD235a). Monocytic marker: (CD14, CD15), and common progenitors markers: (CD5CD34, HLA-DR), CD45 and CD38. If the tubes was not processed within 2 hours, $1 \mathrm{ml}$ of fixative ( $4 \mathrm{~g}$ paraformaldehyde in $100 \mathrm{ml} \mathrm{PBS}$ with $0.1 \% \mathrm{Na}$ azide, $\mathrm{pH} 7.4$ ) was added and the tubes were kept at $4^{\circ} \mathrm{C}$ until analyzed within 24 hours. A minimum of 10,000 events were studied. Gating of the blast cell population was carried out based on its forward and side scatter properties. The percentage of blast cells positive for the relevant studied marker was determined as a percentage from the gated blast cells population. The negative isotypic control was set at $0.5 \%$. Cells were considered positive for a certain marker when $\geq 20 \%$ of cells expressed it, except for CD34, and intracellular MPO where its expression by $10 \%$ of cells was sufficient to confer positive.

\subsection{Statistical Analysis}

Statistical analyses were performed using SPSS version 19. Data were summarized as median, range, percentage or frequency.

\section{Results}

A Clinical and laboratory characteristic of acute leukemia patients group was demonstrated in Table 1 . Based on morphology and immunophenotypic analysis of leukemic cells, out of these 144 cases, there were 88 cases of AML (61.1\%) and 56 cases of ALL (38.9\%). The commonest FAB subtype in AML group in our series was AML-M2 (31.8\%) followed by M4-M5 (27.3\%). AML-M0-M1 accounted for $18.2 \%$ of AML cases, while AML-M6 and AML-M7 represented $3.4 \%$ and $5.6 \%$ respectively. As regard ALL, there were 48 cases (85.7\%) with B-ALL and 8 cases (14.3\%) with T-ALL. Flow cytometric pattern of antigen expression for determination of maturation stage as HLA-DR and CD34 were demonstrated in Table 2. The commonest expression of HLADR was seen in patients with M0-M1 AML (93.8\%), and in B type of ALL (91.6\%). Expression of CD34 also was commonest seen in M0-M1 AML subtype (93.8\%), and in B type of ALL (75\%). The combined use of HLA-DR and CD34 were important in distinguishing cases of M3 AML from other subtypes of AML, negativity of both 
Table 1. Clinical and laboratory characteristics of AL patients group.

\begin{tabular}{|c|c|}
\hline & $\mathrm{N} \%$ \\
\hline Age median (range) & $40(2-90)$ \\
\hline Sex male:female & $108: 36(2.6: 1)$ \\
\hline Fever & $72(50 \%)$ \\
\hline Hepatomegaly & $12(8.3 \%)$ \\
\hline Splenomegaly & $72(50 \%)$ \\
\hline Lymphadenopathy & $24(16.7 \%)$ \\
\hline Bone tenderness & $32(22.2 \%)$ \\
\hline Bleeding tendency & $28(19.4 \%)$ \\
\hline $\mathrm{Hb}$ median (range) & $6.35(2.56-12.4)$ \\
\hline WBCs median (range) & $20.95(1.3-378)$ \\
\hline Platelets median (range) & $40-5(8-951)$ \\
\hline Peripheral blood blast median (range) & $44.5(0-98.5)$ \\
\hline \multicolumn{2}{|l|}{ FAB classification } \\
\hline M0 - M1 & $16(18.2 \%)$ \\
\hline M2 & $28(31.8 \%)$ \\
\hline M3 & $12(13.7 \%)$ \\
\hline M4 - M5 & $24(27.3 \%)$ \\
\hline M6 & $3(3.4 \%)$ \\
\hline M7 & $5(5.6 \%)$ \\
\hline B-ALL & $48(85.7 \%)$ \\
\hline T-ALL & $8(14.3 \%)$ \\
\hline
\end{tabular}

Table 2. Frequency of $\mathrm{HLADR}^{+}$and $\mathrm{CD} 34^{+}$expression of $\mathrm{AL}$ patients group.

\begin{tabular}{|c|c|c|c|c|c|c|c|c|}
\hline & $\begin{array}{c}\text { M0 - M1 } \\
(\mathrm{n}=16) \\
\mathrm{N} \%\end{array}$ & $\begin{array}{c}\text { M2 } \\
(\mathrm{n}=28) \\
\mathrm{N} \%\end{array}$ & $\begin{array}{c}\text { M3 } \\
(\mathrm{n}=12) \\
\mathrm{N} \%\end{array}$ & $\begin{array}{c}\text { M4 - M5 } \\
(\mathrm{n}=24) \\
\mathrm{N} \%\end{array}$ & $\begin{array}{c}\text { M6 } \\
(\mathrm{n}=3) \\
\mathrm{N} \%\end{array}$ & $\begin{array}{c}\text { M7 } \\
(\mathrm{n}=5) \\
\mathrm{N} \%\end{array}$ & $\begin{array}{c}\text { B-ALL } \\
(\mathrm{n}=48) \\
\mathrm{N} \%\end{array}$ & $\begin{array}{c}\text { T-ALL } \\
(\mathrm{n}=8) \\
\mathrm{N} \%\end{array}$ \\
\hline \multirow{2}{*}{$\mathrm{HLADR}^{+}$} & 15 & 24 & 0 & 20 & 1 & 2 & 44 & 1 \\
\hline & $93.8 \%$ & $85 \%$ & $0 \%$ & $83.3 \%$ & $33.3 \%$ & $40 \%$ & $91.6 \%$ & $12.5 \%$ \\
\hline \multirow{2}{*}{$\mathrm{CD}_{3} 4^{+}$} & 15 & 20 & 0 & 12 & 1 & 2 & 36 & 1 \\
\hline & $93.8 \%$ & $71.4 \%$ & $0 \%$ & $50 \%$ & $33.3 \%$ & $40 \%$ & $75 \%$ & $12.5 \%$ \\
\hline \multirow{2}{*}{$\mathrm{HLADR}^{+}, \mathrm{CD} 34^{+}$} & 13 & 20 & 0 & 8 & 1 & 0 & 32 & 1 \\
\hline & $81.3 \%$ & $71.4 \%$ & $0 \%$ & $33.3 \%$ & $33.3 \%$ & $0 \%$ & $66.6 \%$ & $12.5 \%$ \\
\hline \multirow{2}{*}{$\mathrm{HLADR}^{-}, \mathrm{CD} 34^{-}$} & 0 & 4 & 12 & 0 & 0 & 1 & 1 & 7 \\
\hline & $0 \%$ & $14.2 \%$ & $100 \%$ & $0 \%$ & $0 \%$ & $20 \%$ & $8.3 \%$ & $87.5 \%$ \\
\hline
\end{tabular}

antigens was seen in $100 \%$ of M3 cases. As regard the expression pattern of primary panels' markers Table 3, the leukemic cells in all cases of AML commonly express various combinations of myeloid markers CD13, CD33, CD14 and CD15. Surface CD13 was the most commonly present in all AML subtypes, its percent was $93.1 \%$, CD33 was the next most commonly expressed antigen 
Table 3. Primary panel expression of AL patients group.

\begin{tabular}{ccccccccc}
\hline & $\begin{array}{c}\mathrm{M} 0-\mathrm{M} 1 \\
(\mathrm{n}=16)\end{array}$ & $\begin{array}{c}\mathrm{M} 2 \\
(\mathrm{n}=28)\end{array}$ & $\begin{array}{c}\mathrm{M} 3 \\
(\mathrm{n}=12)\end{array}$ & $\begin{array}{c}\mathrm{M} 4-\mathrm{M} 5 \\
(\mathrm{n}=24)\end{array}$ & $\begin{array}{c}\mathrm{M} 6 \\
(\mathrm{n}=3)\end{array}$ & $\begin{array}{c}\mathrm{M} 7 \\
(\mathrm{n}=5)\end{array}$ & $\begin{array}{c}\mathrm{B}-\mathrm{ALL} \\
(\mathrm{n}=48)\end{array}$ & $\begin{array}{c}\mathrm{T}-\mathrm{ALL} \\
(\mathrm{n}=8)\end{array}$ \\
\hline $\mathrm{CD} 13^{+}$ & 16 & 28 & 12 & 24 & 1 & 1 & 20 & 2 \\
& $100 \%$ & $100 \%$ & $100 \%$ & $100 \%$ & $33.3 \%$ & $20 \%$ & $41.7 \%$ & $25 \%$ \\
$\mathrm{CD} 33^{+}$ & 12 & 28 & 12 & 24 & 0 & 0 & 4 & 0 \\
& $75 \%$ & $100 \%$ & $100 \%$ & $100 \%$ & $0 \%$ & $0 \%$ & $8.3 \%$ & $0 \%$ \\
$\mathrm{CD} 14^{+}$ & 0 & 0 & 0 & 16 & 0 & 0 & 0 & 0 \\
& $0 \%$ & $0 \%$ & $0 \%$ & $66.7 \%$ & $0 \%$ & $0 \%$ & $0 \%$ & $0 \%$ \\
$\mathrm{CD} 15^{+}$ & 0 & 0 & 0 & 12 & 0 & 0 & 0 & 0 \\
& $0 \%$ & $0 \%$ & $0 \%$ & $50 \%$ & $0 \%$ & $0 \%$ & $0 \%$ & $0 \%$ \\
$\mathrm{CD} 10^{+}$ & 0 & 0 & 0 & 0 & 0 & 0 & 40 & 2 \\
& $0 \%$ & $0 \%$ & $0 \%$ & $0 \%$ & $0 \%$ & $0 \%$ & $83.3 \%$ & $25 \%$ \\
$\mathrm{CD}^{2} 9^{+}$ & 0 & 8 & 1 & 0 & 1 & 0 & 46 & 0 \\
& $0 \%$ & $42.8 \%$ & $8.3 \%$ & $0 \%$ & $33.3 \%$ & $0 \%$ & $95.8 \%$ & $0 \%$ \\
$\mathrm{CD}^{2} 2^{+}$ & 0 & 0 & 0 & 8 & 0 & 0 & 48 & 1 \\
& $0 \%$ & $0 \%$ & $0 \%$ & $33.3 \%$ & $0 \%$ & $0 \%$ & $100 \%$ & $12.5 \%$ \\
$\mathrm{CD}^{+}$ & 0 & 0 & 0 & 2 & 0 & 0 & 10 & 8 \\
& $0 \%$ & $0 \%$ & $0 \%$ & $8.3 \%$ & $0 \%$ & $0 \%$ & $20.8 \%$ & $100 \%$ \\
$\mathrm{CD}^{+}$ & 0 & 0 & 0 & 2 & 0 & 0 & 8 & 4 \\
& $0 \%$ & $0 \%$ & $0 \%$ & $8.3 \%$ & $0 \%$ & $0 \%$ & $16.7 \%$ & $50 \%$ \\
$\mathrm{CD}^{+}$ & 2 & 0 & 0 & 0 & 0 & 0 & 2 & 6 \\
& $12.5 \%$ & $0 \%$ & $0 \%$ & $0 \%$ & $0 \%$ & $0 \%$ & $4.2 \%$ & $75 \%$ \\
$\mathrm{CD}^{+}$ & 8 & 10 & 2 & 2 & 0 & 0 & 10 & 8 \\
& $50 \%$ & $35.7 \%$ & $16.7 \%$ & $8.3 \%$ & $0 \%$ & $0 \%$ & $20.8 \%$ & $100 \%$ \\
\hline
\end{tabular}

showing $86.4 \%$ positivity in all AML categories. Surface CD14 and CD15 positivity were more commonly associated with the monocytic leukemias $(66.7 \%$ and $50 \%$, respectively). Combinations of $\mathrm{CD} 14^{+}$expression and $\mathrm{CD}^{+} 5^{+}$detect $100 \%$ of M4-M5 cases. As regard ALL B-type CD22 and CD19 were the most commonly presented antigen ( $100 \%$ and $95.8 \%$, respectively). Expression of CD2 and CD7 was seen in $100 \%$ of T-ALL cases while expression of CD3 and CD5 was seen in 50\%, 75\% respectively. Expression pattern of secondary panels' markers were demonstrated in Table 4. Surface CD117 was expressed in all AML cases with some variation. The highest percentage of CD117 positivity was seen in M6 (100\%), and M7 (100\%). The commonest expression of MPO was seen in patients with M3 AML (91.7\%). MPO was not seen in any of our M6 or M7 cases. As regard ALL, there was no detection of CD117 or MPO in either B- or T-ALL cases. On the other hand, both $\mathrm{CCD} 79 \mathrm{a}$ and $\mathrm{CCD} 3$ were negative in all AML cases in contrast to their positivity in all B-ALL and T-ALL cases respectively. The expression of megakaryocyte-associated Antigens CD41, CD42 and CD61, was seen in all cases of AML-M7. Regarding CD235a, its expression was restricted to AML-M6 cases. In our study, the aberrancy expressions were found in 66 leukemic cases (45.8\%) Table 5, CD7 was the most commonly expressed lymphoid antigen in AML (25\%) (Figure 1), followed by CD19 expression (13.4\%). As regard aberrant expression of myeloid antigens in ALL, CD13 was the most commonly expressed antigen (39.3\%). 



Figure 1. Histogram of flow cytometry showed a case of acute myeloid leukemia positive for the following markers CD45, anti-HLA-DR, CD34, CD33, CD13 and co-expressing CD7.

Table 4. Secondary panel expression of AL patients group.

\begin{tabular}{|c|c|c|c|c|c|c|c|c|}
\hline & $\begin{array}{c}\mathrm{M} 0-\mathrm{M} 1 \\
(\mathrm{n}=16) \\
\mathrm{N} \%\end{array}$ & $\begin{array}{c}\text { M2 } \\
(\mathrm{n}=28) \\
\text { N\% }\end{array}$ & $\begin{array}{c}\text { M3 } \\
(\mathrm{n}=12) \\
\mathrm{N} \%\end{array}$ & $\begin{array}{c}\text { M4 - M5 } \\
(\mathrm{n}=24) \\
\mathrm{N} \%\end{array}$ & $\begin{array}{c}\text { M6 } \\
(\mathrm{n}=3) \\
\mathrm{N} \%\end{array}$ & $\begin{array}{c}\text { M7 } \\
(\mathrm{n}=5) \\
\mathrm{N} \%\end{array}$ & $\begin{array}{c}\text { B-ALL } \\
(\mathrm{n}=48) \\
\mathrm{N} \%\end{array}$ & $\begin{array}{c}\text { T-ALL } \\
(\mathrm{n}=8) \\
\mathrm{N} \%\end{array}$ \\
\hline \multirow{2}{*}{$\mathrm{CD} 117^{+}$} & 13 & 25 & 10 & 13 & 3 & 5 & 0 & 0 \\
\hline & $81.3 \%$ & $89.3 \%$ & $83.3 \%$ & $54.2 \%$ & $100 \%$ & $100 \%$ & $0 \%$ & $0 \%$ \\
\hline \multirow{2}{*}{$\mathrm{MPO}^{+}$} & 5 & 24 & 11 & 13 & 0 & 0 & 0 & 0 \\
\hline & $31.3 \%$ & $85.7 \%$ & $91.7 \%$ & $54.2 \%$ & $0 \%$ & $0 \%$ & $0 \%$ & $0 \%$ \\
\hline \multirow{2}{*}{$\mathrm{cCD}^{+}$} & 0 & 0 & 0 & 0 & 0 & 0 & 0 & 8 \\
\hline & $0 \%$ & $0 \%$ & $0 \%$ & $0 \%$ & $0 \%$ & $0 \%$ & $0 \%$ & $100 \%$ \\
\hline \multirow{2}{*}{${\mathrm{cCD} 79^{+}}^{+}$} & 0 & 0 & 0 & 0 & 0 & 0 & 48 & 0 \\
\hline & $0 \%$ & $0 \%$ & $0 \%$ & $0 \%$ & $0 \%$ & $0 \%$ & $100 \%$ & $0 \%$ \\
\hline \multirow{2}{*}{$\mathrm{CD} 4^{+}$} & 0 & 0 & 0 & 4 & 0 & 0 & 0 & 3 \\
\hline & $0 \%$ & $0 \%$ & $0 \%$ & $16.7 \%$ & $0 \%$ & $0 \%$ & $0 \%$ & $37.5 \%$ \\
\hline \multirow{2}{*}{$\mathrm{CD}^{+}$} & 0 & 0 & 0 & 0 & 0 & 0 & 0 & 6 \\
\hline & $0 \%$ & $0 \%$ & $0 \%$ & $0 \%$ & $0 \%$ & $0 \%$ & $0 \%$ & $75 \%$ \\
\hline $\mathrm{CD}_{4} 1^{+}$, & 0 & 0 & 0 & 0 & 0 & 5 & 0 & 0 \\
\hline $\mathrm{CD}_{4} 2^{+}, \mathrm{CD} 1^{+}$ & $0 \%$ & $0 \%$ & $0 \%$ & $0 \%$ & $0 \%$ & $100 \%$ & $0 \%$ & $0 \%$ \\
\hline \multirow{2}{*}{$\mathrm{CD} 235 \mathrm{a}^{+}$} & 0 & 0 & 0 & 0 & 3 & 0 & 0 & 0 \\
\hline & $0 \%$ & $0 \%$ & $0 \%$ & $0 \%$ & $100 \%$ & $0 \%$ & $0 \%$ & $0 \%$ \\
\hline
\end{tabular}


Table 5. Frequency of aberrant markers in AL patient group.

\begin{tabular}{lcc}
\hline & AML $(\mathrm{n}=88)$ & ALL $(\mathrm{n}=56)$ \\
\hline CD2 & $2(2.3 \%)$ & \\
CD3 & $2(2.3 \%)$ & \\
CD4 & $4(4.5 \%)$ & \\
CD5 & $2(2.3 \%)$ & \\
CD7 & $22(25 \%)$ & \\
CD19 & $10(13.4 \%)$ & \\
CD22 & $8(9.1 \%)$ & $22(39.3 \%)$ \\
CD10 & $0(0 \%)$ & $4(7.1 \%)$ \\
CD13 & & $0(0 \%)$ \\
CD33 & & $0(0 \%)$ \\
CD14 & & \\
CD15 & & \\
\hline
\end{tabular}

\section{Discussion}

Acute leukemia is a heterogeneous disease having diverse phenotypes. Immunophenotyping by flow cytometry is essential for diagnosis of myeloid and lymphoid subtypes. This current study includes 144 leukemic patients, 88 cases diagnosed as AML (61.1\%) and 56 cases diagnosed as ALL (38.9\%). This high percentage of AML may be due to the high percentage of adult patients, adult to child ratio was (2.8:1), and $47 \%$ of ALL patients were children. These data were in agreement with the most of previous studies in Egypt [4], which reported 68.9\% and 31.1\% AML and ALL, respectively, and a Jordan study, in which percentages of AML and ALL were (52\%) and (47\%) respectively [7].

Regarding the FAB classification of acute myeloid leukemia M2 subtype was the most frequent (31.8\%) followed by M4 - M5 subtypes (27.3\%) and this is matched with results of many studies in Egypt [8] [9]. However, other national and international studies have reported that M4 - M5 subtypes are the most common [4] [10]. For ALL, B-ALL was more frequent than T-ALL (85.7\%) \& (14.3\%) respectively which agreed with other studies [11] [12].

Surface CD34 and HLA-DR are stem cell/hematopoietic precursors and commonly used in flow cytometric immunophenotyping of acute leukemia as immaturity demarcation antigens. Surface CD34 is a transmembrane protein normally expressed in hematopoietic stem cells and early thymic T-cell precursors. Surface CD34 is one of the most widely used markers of hematopoietic stem cells (HSCs) and is involved in the inhibition of HSCs differentiation, expansion, signaling transduction and anti-adhesion [13].

Our study finding revealed that $100 \%$ of $\mathrm{M} 3$ cases were double negative for HLA-DR-/CD34- and this is accordance with the results of many studies concerned with AML-M3 immunophenotyping when compared with other types of AML, M3 typically displays absent or weak CD34, absent HLA-DR [14] [15]. 
The frequency of CD34 in B-ALL cases was 75\%, but in T-ALL was $12.5 \%$. HLA-DR frequency in B-ALL was (91.6\%) and for T-ALL was (12.5\%). These results matched with Sharma et al., who found that CD34 expression in ALL were seen in $67.3 \%$ of all ALL cases and the expression was more frequent in B-ALL (70.3\%) as compared to T-ALL (51\%) [16]. Another Indian study found that CD34 positivity was much higher in B-lineage ALL (82\%) than in T-ALL (35\%), $(p<0.0001)$ [17]. With ALL, expression of CD34 might be associated with immaturity due to developmental arrest or asynchronous expression with mature antigens. There was a significant association of CD34 with aberrant expression of myeloid markers in B-ALL. Many studies found strong correlation between high CD34 and myeloid antibody co-expression in the blasts of ALL patients [5] [18], but in the present study we didn't find significant correlation. In the present study, there was a strong association between HLA-DR and CD34 positivity and AML-M0-M1 subtypes while Callea et al. reported strong association with AML-M4/M5 subtypes [19].

Most of leukemic cases show specific immunological markers but on the other hand aberrant immunological markers were detected in considerable number of cases, aberrant phenotype incidence is controversial and dissimilar results have been reported by different groups [1].

In this study, the aberrancy percentage was $45.8 \%$ of all leukemic patients, was found in 66 patients, lymphoid antigen markers expression in AML was in 40 patients (45.5\%), and aberrancy incidence of myeloid antigen expression on ALL was in 26 patients (46.4\%). Some studies showed comparable results, in which aberrant myeloid antigen expression was seen in $42.5 \%$ of ALL cases and $47 \%$ of AML cases showed aberrant lymphoid antigen expression [16] [20]. On the other hand many studies showed lower frequency of aberrant immunophenotyping [7] [21].

In our study the most frequent aberrant myeloid marker in ALL was CD13. Surface CD13 was positive in 22 ALL patients (39, 3\%) 20/48 patients of them were B ALL (41.7\%), 2/8 patients with TALL (25\%). Followed by CD33, which was positive in 4 ALL patients (7.1\%) all of them was B ALL. The frequency of CD13 and CD33 in ALL was comparable with data published by WHO 2008 [22], which stated that CD13 and CD33 are often the most frequent myeloid markers expressed in ALL cases. Many studies reported that CD13 was the most frequently expressed antigen in ALL [5] [17] [23]. On the other hand some studies findings showed lower frequencies of CD13 and CD33 of 15/165 patients (9.1\%) of total ALL cases, and 15/132 (11.3\%) respectively [24].

The most frequently lymphoid antigen aberrantly expressed in AML was CD7 (25\%), followed by CD19 (13.4\%) then CD22 (9.1\%).This in accordance with most of studies based on assessments of aberrant markers in AML which show similar frequency of CD7 positivity in AML [4] [25] [26]. In contrast with our observation El-Sissy et al. observed that CD7 was expressed in a minority of patients with AML 4/34 (11.8\%) [20], and Shen et al. reported CD7 expression in 28/222 (12.6\%) [27]. Surface CD7 was positive in all subtypes of AML except M6 
and M7 and show high frequency in M0-M1 followed by M2 (50\%) and (35.7\%) respectively. Some studies reported that cases of AML which had been associated with the expression of $\mathrm{CD} 7$ had a poor prognosis [26]. Surface CD7 expression in AML is associated with the immature antigens CD34, HLA-DR [28] and these findings are in accordance with our findings in which CD7, HLA DR and CD34 are co-expressed in 16 AML cases (18.2\%) with subtype M0-1 and M2 but in M3, CD7 positive patients associated with negative HLADR and CD34. Some studies contend that AML with CD7 may originate from early hematopoietic precursors, and its expression at diagnosis associated with biologic aggressiveness and a low remission rate in a significant proportion of AML patients [29] [30]. Surface $\mathrm{CD} 4$ is considered as aberrant antigen only when expressed in cases other than M4 - M5, because it is a differentiation marker in monocytic AML [3], so in our study we considered that no aberrancy regarding CD4 because of its expression M4 - M5 AML cells.

As regard CD5, CD2, and CD3 were shown frequency of $2 \%$ in AML cases of this study. Surface CD5 expression is not common in AML and some authors proposed CD5 expression as a positive prognostic indicator in AML patients and a negative prognostic indicator in B-ALL patients [31]. In accordance with our results $\mathrm{CD} 2$ was expressed in 5\% AML cases in a study by Abdulateef et al. [3] and Jiang et al. [13] reported similar results $4.9 \%$.

In our study, B-lineage antigen CD22 cases of AML was found in 8 cases (9.1\%), all of them of M4 - M5 subtype and this in agreement with that reported by Faleh et al. which reported that CD22 is one of the most common lymphoid markers co-expressed aberrantly in patients with AML [32].

Correlation with treatment response had not been carried out so definite comment upon overall prognostic significance of these aberrant markers cannot make in our study. However; presence of aberrancy helps in identifying a neoplastic process.

\section{Conclusion}

The multiparametric immunophenotyping analysis of AL is sufficient for diagnosis and classification of leukemia. The frequencies of aberrant markers in AL were matched with many published data. The role of aberrancy in prognosis of acute leukemia needs further study with larger sample size and correlation of the frequency of the aberrant markers with prognostic factors, genetic abnormality and therapeutic response.

\section{Conflict of Interest}

The authors declare that there is no conflict of interest regarding the publication of this paper.

\section{References}

[1] Sarma, A., Hazarika, M., Das, D., et al. (2015) Expression of Aberrant CD Markers 
in Acute Leukemia: A Study of 100 Cases with Immunophenotyping by Multiparameter Flow Cytometry. Cancer Biomarkers, 15, 501-505.

https://doi.org/10.3233/CBM-150482

[2] Jahedi, M., Shamsasenjansti, K. and Sanaat, Z. (2014) Aberrant Phenotype in Iranian Patients with Acute Myeloid Leukemia. Advanced Pharmaceutical Bulletin, 4, 43-47.

[3] Abdulateef, N., Ismail, M. and Aljedani, H. (2014) Clinical Significance of Co-Expression of Aberrant Antigens in Acute Leukemia: A Retrospective Cohort Study in Makah Al Mukaramah, Saudi Arabia. Asian Pacific Journal of Cancer Prevention, 15, 221-227. https://doi.org/10.7314/APJCP.2014.15.1.221

[4] Salem, D.A. and Abd El-Aziz, S.M. (2012) Flow Cytometric Immunophenotypic Profile of Acute Leukemia: Mansoura Experience. Indian Journal of Hematology \& Blood Transfusion, 28, 89-96. https://doi.org/10.1007/s12288-011-0110-2

[5] Monika, G., Sumiti, G., Sunita, S., et al. (2017) Aberrant Expression of CD Markers in Acute Lymphoblastic Leukemia: A Diagnostic Clue of Malignancy or Compounding Confusions. Indian Journal of Science Research, 8, 81-85.

[6] Lopes, T., Andrade, K., Camelo, N., et al. (2014) Influence of Aberrant Myeloid Expression on Acute Lymphoblastic Leukemia in Children and Adolescents from Maranhão, Brazil. Genetics and Molecular Research, 13, 10301-10307.

https://doi.org/10.4238/2014.December.4.25

[7] Momani, A., Abbasi, N., Alsokhni, H., et al. (2016) Aberrant Antigen Expression in Patients with Acute Leukemias, Experience of King Hussein Medical Center in Jordan. Journal of Research in Medical Sciences, 23, 59-67.

[8] Abd El-Rahman, A., Abdel-Hamid, S., Makhlouf, M., et al. (2010) Detection of CXCL12 Gene Polymorphism and CXCR4 Expression in Egyptian Acute Myeloid Leukemia Patients. Journal of American Science, 6, 318-330.

[9] El Sharkawy, N. and Abdel Hamid, T. (2010) Internal Tandem Duplication of FLT3 Gene in Egyptian Adult Acute Myeloid and Acute Lymphoblastic Leukemia. Journal of American Science, 6, 14-22.

[10] Harani, M.S., Adil, S.N., Shaikh. M.U., et al. (2005) Frequency of FAB Subtypes in Acute Myeloid Leukemia Patients at Aga Khan University Hospital Karachi. Journal of Ayub Medical College Abbottabad, 17, 26-29.

[11] Omran, H.A., Shabani, M., Shahrestani, T., et al. (2007) Immunophenotypic Subtyping of Leukemic Cells from Iranian Patients with Acute Lymphoblastic Leukaemia: Association to Disease Outcome. Iranian Journal of Immunology, 4, 15.

[12] Gujral, S., Badrinath, Y. and Kumar, A. (2009) Immunophenotypic Profile of Acute Leukemia: Critical Analysis and Insights Gained at a Tertiary Care Center in India. Cytometry Part B: Clinical Cytometry, 76, 199-205. https://doi.org/10.1002/cyto.b.20451

[13] Jiang, Z., Wu, D., Lin, S., et al. (2016) CD34 and CD38 Are Prognostic Biomarkers for Acute B Lymphoblastic Leukemia. Biomarker Research, 4, 23. https://doi.org/10.1186/s40364-016-0080-5

[14] Wang, X.B., Zheng, J.E., Gu, J.X., et al. (2005) Correlation of Immunophenotype to Cytogenetics and Clinical Features of Adult Acute Myeloid Leukemia. Ai Zheng, 24, 667-671.

[15] Alejandro, S., Mendoza, X., Qing, M., et al. (2016) HLA-DR Antigen-Positive Acute Promyelocytic Leukemia. Experimental and Molecular Pathology, 101, 197-200. https://doi.org/10.1016/j.yexmp.2016.07.013 
[16] Sharma, M., Sachdeva, M.U., Varma, N., et al. (2016) Characterization of Immunophenotypic Aberrancies in Adult and Childhood Acute Lymphoblastic Leukemia: A Study from Northern India. Journal of Cancer Research and Therapeutics, 12, 620-626. https://doi.org/10.4103/0973-1482.147716

[17] Vitale, A., Guarini, A., Ariola, C., et al. (2007) Absence of Prognostic Impact of CD13 and/or CD33 Antigen Expression in Adult Acute Lymphoblastic Leukemia: Results of the GIMEMA ALL 0496 Trial. Haematologica, 92, 342-348.

https://doi.org/10.3324/haematol.10385

[18] Sharma, R.K., Purohit, A., Somasundaram, V., et al. (2014) Aberrant Myeloid Antigen Co-Expression Is Correlated with High Percentages of CD34-Positive Cells among Blasts of Acute Lymphoblastic Leukemia Patients: An Indian Tertiary Care Center Perspective. Blood Research, 49, 241-245.

https://doi.org/10.5045/br.2014.49.4.241

[19] Callea, V., Morabito, F., Martino, B., et al. (1991) Diagnostic and Prognostic Relevance of the Immunophenotype in Acute Myelocytic Leukemia. Tumori Journal, 77, 28-31. https://doi.org/10.1177/030089169107700107

[20] El-Sissy, A.H., El-Mashari, M.A., Bassuni, W.Y., et al. (2006) Aberrant Lymphoid Antigen Expression in Acute Myeloid Leukemia in Saudi Arabia. Journal of the Egyptian National Cancer Institute, 18, 244-249.

[21] Khurram, M., Jafri, S. and Mannan, A. (2010) Frequency of Aberrant Expression of Cd Markers in Cases of Acute Leukemia. Medical Journal of Islamic World Academy of Sciences, 18, 55-60.

[22] Borowitz, M.J. (2008) Acute Leukemia of Ambiguous Lineage. In: Swerdlow, S.H., Campo, E. and Harris, N.L., Eds., WHO Classification of Tumours of Haematopoietic and the Lymphoid Tissues, 4th Edition, IARC Press, Lyon, 150-155.

[23] Seegmiller, A.C., Kroft, S.H., Karandikar, N.J., et al. (2009) Characterization of Immunophenotypic Aberrancies in 200 Cases of B Acute Lymphoblastic Leukemia. American Journal of Clinical Pathology, 132, 940-949. https://doi.org/10.1309/AJCP8G5RMTWUEMUU

[24] Haddad, F., Wraikat, A., Khasawneh, R., et al. (2014) Immunophenotypic Diagnosis of Acute Lymphoblastic Leukemia Using Flow Cytometry; Experience at King Hussein Medical Center. Journal of the Royal Medical Services, 21, 21-26. https://doi.org/10.12816/0004537

[25] Bhushan, B., Chauhan, P.S., Saluja, S., et al. (2010) Aberrant Phenotypes in Childhood and Adult Acute Leukemia and Its Association with Adverse Prognostic Factors and Clinical Outcome. Clinical and Experimental Medicine, 10, 33-40. https://doi.org/10.1007/s10238-009-0067-8

[26] Al-Anizi, W.M. and Al-Mashta, M.A. (2017) The Frequency of Aberrant Lymphoid Antigens Expression in 202 Iraqi Patients with De Novo Acute Myeloid Leukemia. Iraqi Journal of Hematology, 6, 49-54. https://doi.org/10.4103/ijh.ijh_17_17

[27] Shen, H.Q., Tang, Y.M., Yang, S.L., et al. (2003) Immunophenotyping of 222 Children with Acute Leukemia by Multi-Color Flow Cytometry. Chinese Journal of Pediatrics, 41, 334-337.

[28] Elyamany, G., Fadalla, K. and Abdulaaly, A.A. (2013) Abnormal Expression of CD79a, CD56 and CD7 in Acute Myeloid Leukemia. Pathology Discovery, 1, 6. https://doi.org/10.7243/2052-7896-1-6

[29] Saxena, A., Sheridan, D.P., Card, R.T., et al. (1998) Biologic and Clinical Significance of CD7 Expression in Acute Myeloid Leukemia. American Journal of Hematology, 58, 278-284. 
https://doi.org/10.1002/(SICI)1096-8652(199808)58:4<278::AID-AJH5>3.0.CO;2-N

[30] Tiftik, N., Bolaman, Z., Batun, S., et al. (2004) The Importance of CD7 and CD56 Antigens in Acute Leukaemias. International Journal of Clinical Practice, 58, 149-152. https://doi.org/10.1111/j.1368-5031.2004.0018.x

[31] Basturk, A., Akinci, S., Hacibekiroglu, T., et al. (2015) Prognostic Significance of Flow Cytometry Findings in Turkish Adult Acute Leukemia Patients. European Review for Medical and Pharmacological Sciences, 19, 3360-3366.

[32] Faleh, A.A., Al-Quozi, A., Alaskar, A., et al. (2015) Clinical Features and Outcome of Acute Myeloid Leukemia, a Single Institution Experience in Saudi Arabia. Journal of Applied Hematology, 6, 6-12. https://doi.org/10.4103/1658-5127.155171 